\title{
Fruity response efficacy and fruit consumption among a group of civil servants of Oyo State, Nigeria
}

\author{
Ibrahim, Fausat M. \\ Department of Agricultural Extension and Management, Federal College of Forestry, P.M.B. \\ 5087, Ibadan, Oyo State, Nigeria. \\ email: motunib@yahoo.com, mobile phone no: +2348055822100
}

\section{ABSTRACT}

Fruit consumption has continued to be of pivotal importance in health optimization. Unfortunately, data signifying same in many African sub-populations seem deficient or unreadily available. Hence, fruit consumption in relation with fruity response efficacy, gender, age, education, marital status and financial standing was surveyed among a group of civil servants of Nigeria. Five hundred and sixty-three copies of randomly administered questionnaires yielded data whose analyses reveal that fruity response efficacy and age are significantly related to fruit consumption $(p<0.05)$ while gender, marital status, education and financial standing are not $(p>0.05)$. Being older and improving perception of the role of fruit consumption in health optimization are associated with greater fruit consumption. Gender, marital status, general education and financial conditions were non determinants of this consumption.

Keywords: fruit consumption, response efficacy, civil servants, Nigeria.

\section{INTRODUCTION}

Dietary thoughtfulness is one of the chief cornerstones of preventing chronic illnesses such as cardiovascular diseases and some cancers (WHO, 2003; Robertson et. al. 2004; Hall et. al., 2009). Although chronic illnesses had always been problems of developed societies (Boutayeb and Boutayeb, 1995), the scenario appears to have changed dramatically. Africa is at an early stage of epidemiological transition from communicable to chronic, non-communicable diseases (NCD) (Oladapo et. al., 2010; Kimani-Murage et. al., 2010). Worse still, $80 \%$ of chronic-diseases related deaths occur in low and middle-income countries (Daar et. al., 2007) and chronic illnesses will be the cause of 7 out of every 10 deaths in developing countries $(\mathrm{WHO}$, 2003; Pearson, 1996). These developing countries have greater healthcare challenges, in comparison to developed countries. Already, data shows that chronic, non-communicable diseases are significant health problems in developing countries, Nigeria inclusive. For instance, the analysis of retrospective data by Unachukwu et. al., (2008) to ascertain pattern of chronic illnesses between 2000-2004 in the University of Port Harcourt Teaching Hospital (UPTH), Nigeria, shows that NCDs constitute $56.2 \%$ of total medical admissions.

Fruit consumption is indeed a panacea for health optimization. It is categorically recommendable.
Certainly, the future of human health depends heavily on factors such as high fruit and vegetable consumption. This claim is supported by substantial evidence. For example, Boutayeb and Boutayeb (1995) reported that $4.9 \%$ of global death in the year 2002 is attributable to low fruit and vegetable consumption. Again, Schneider et. al. (2007) found that low fruit and vegetable intake accounted for $3.2 \%$ of total deaths in South Africa in the year 2000 . Fruit consumption is very beneficial to health, such as contributing significantly to the physical functioning of cancer survivors (Demark-Wahnefried et. al., 2009). It is positively linked with psychosocial factors such as knowledge (Yeh et. al., 2010); self efficacy (Horwath et. al., 2010); outcome expectations (Reynolds et. al., 1999); perceived health benefits (Townsend et. al., 1998) and authoritative parenting style towards adolescents (Kremers et. al., 2003).

Unfortunately, many studies have reported low fruit consumption across different population: elderly people in New York (Frongillo et. al., 2010), Finnish adolescents (Hoppu et. al., 2010), American-Indian and Alaska-Native Adolescents (Story et. al., 1998) and Finnish young men (Bingham et. al., 2010). Regrettably, data are seemingly deficient (Hall et. al., 2009) or readily unavailable about many African subpopulations. This work therefore examined fruit consumption, while focusing on the effect of fruity response efficacy, gender, age, education, marital status and an index of financial standing on this 
consumption, among a group of civil servants of Oyo State, Nigeria. Fruit as opposed to vegetable consumption was of greater interest because increment in fruit consumption is relatively easier: fruit is consumable at work, home, on transit, and requires no cooking. This is probably why multicomponent school interventions have been more effective in increasing fruit intake, rather than vegetable intake (French and Stables, 2003). Besides, fruit consumption is a little more important than vegetable consumption in reducing risk of some cancer (Gandini et al., 2000).

\section{METHODS}

Design, Instrument, Population and Sampling: This work is a cross-sectional survey which targeted civil servants of Oyo State, South Western Nigeria. Semi-structured, self administered questionnaires were used in data collection. Oyo State people are predominantly Yoruba, but largely bilinguals, speaking both English and Yoruba. Civil servants constitute a microcosm of the larger society, information obtained from them can be extrapolated. Those who work in the ministries are specifically targeted as the civil service is made up of other worker groups like health workers, teachers and higher institution lecturers. This is to attenuate the influence of job related dynamics on responses. The work of ministry workers does not involve specialized form of training like health workers' and it also does not predispose to access to information like teachers' and higher institution lecturers'. This makes ministry workers to be more representative of the larger society. Information obtained from the Ministry of Finance shows that the total population of the staff of the 16 ministries of the State is 4740 . The required sample size at $95 \%$ confidence level and confidence interval of 4 is 533 . This was increased to 600 to give room for problematic questionnaires. Four ministries with the highest number of staff were selected for the study. The lists of these staff served as a sampling frame from where 600 respondents were randomly drawn. Out of 567 retrieved questionnaires, 563 were worth analyzing.

Variables and Measures: Fruit consumption is the dependent variable of study. Fruit is defined as sweet, fleshy, edible part of plants that contain seed(s). Fruity response efficacy is an independent variable of study, defined as perceived role of fruit consumption in health optimization. Response efficacy is a construct of the protection motivation theory (PMT). PMT argues, among other things that the probability of taking up recommendable health behaviour is positive function of response efficacy.
Response efficacy is the belief that a recommended behaviour will be successful in reducing a threat (Rogers, 1983; Stroebe, 2000). This argument is naturally appealing and the findings of Townsend et. al. (1998) nod in this direction. Gender, age, education, marital status and financial standing are the independent socio-demographic and economic characteristics that are also expected to predict fruit consumption. Socialization theories support the expectation of gendered differences in fruit consumption. These theories concord that females are predisposed toward the caregiver role, making women to be more compassionate, nurturing and protective than men [Beutel and Marini, 1995]. This mentality may be extended to fruit consumption, as it a protective option. Increasing age usually comes along with increasing responsibility. This makes it plausible to expect increasing fruit consumption with increasing age. Education improves life chances and access to information, health information inclusive. Hence, the expectation of positivity between education and fruit consumption. Within the marital status sub groups, married people are expected to exhibit greater fruit consumption. Story et.al. (1998) reported that 'low family connectedness' is associated with low fruit and vegetable intake. Moreno et.al, (2010) similarly asserted that 'family meals could serve as role models for healthy eating behaviors'. It is quite rational to assume greater fruit consumption with increasing financial capability.

Fruit consumption was assessed with a 7-day fruit consumption recall index. Fruit consumption within 24-hour, 3-day and 7-day period of investigation attracted a score of 1,2 and 3 respectively. Nonconsumption within this period attracted 0 . Fruity response efficacy was assessed with a 5 -item rating scale. Responses to each item was rated 1 to 4 . A reliability analysis of these items after a pilot study among members of staff in a non-participating ministry yielded a Crobach alpha value of 0.714 . Items were scored such that higher score imply better response efficacy. Possible scores are 0-4, 5-20 for the index of fruit consumption and scale of fruity response efficacy respectively. Gender and marital status were nominally assessed by requiring respondents to tick as it applied to them. Respondents stated their age. Education was assessed as a continuous variable, with a score of 1 to 8 accorded these education attainments respectively: no formal education, primary education, secondary education, Advanced levels (AL)/Ordinary National Diploma (OND)/National Certificate of 
Education (NCE), Higher National Diploma (HND)/B.Sc., Post Graduate Diploma (PGD), M.Sc., and Ph.D. Financial standing was assessed with level in service. The civil service is a rank-like organization where staff are expected to rise through the ladder with increasing years in service, education and other requirements. The minimum level in service is 1 , maximum is 16 .

Data Analysis: Simple percentile analysis and the mode were used to assess some profile of respondents. The index of fruity response efficacy was computed for each respondent by simply aggregating the scores accorded their items. One sample Kolmogorov Smirnov test (for normalcy) showed that data distributions were not significantly different from normal distributions $(p>0.05)$. One way ANOVA was used to assess significant differences in the means across sub-groups of marital status. $T$-test was used to test this difference between gender sub groups. Levene's test for homogeneity of variance was used to assess the homogeneity of variance across sub-groups of independent, categorical variables. Eta and eta ${ }^{2}$ were used as measures of effect sizes. Pearson's correlation coefficient $(r)$, multiple coefficient of determination $\left(R^{2}\right)$ and beta coefficient $(\beta)$ were used to assess the relationship between fruit consumption, fruity response efficacy, age, education, and financial standing. All data analyses were accomplished with Statistical Package for Social Sciences (version 15.0, 2006, SPSS, Inc, Chicago, IL).

\section{RESULTS AND DISCUSSION}

Males were $50.4 \%$ while females were $49.6 \%$, reflecting a bipolar distribution of respondents in terms of gender. The mean age of respondents was 37.2 , the mode was $37(\min .=21$; $\max .=65)$. This probably reflects a young work force. The modal education attainment subgroup is the HND/B.Sc sub group, as almost half of total respondents were interestingly graduates (45.1\%). An overwhelming majority of respondents are married $(67.1 \%)$ while the percentage of those who are single, divorced and widowed are 28.1, 3.6 and 1.2 respectively. Respondents varied considerably with regard to financial standing (level in service), with the highest concentrations in level 8 and $9(14.4 \%$ and $14.7 \%$ respectively). However, a noticeable percentage $(15.1 \%)$ of respondents did not indicate their level in service. This evasion is probably to avoid divulging identity on the part of respondents.

The mean fruit consumption score is $2.05(\mathrm{~min} .=0$, max. =3) while the mean fruity response efficacy score is 17.58 ( $\min .=10, \max .=20)$. The analysis of the influence gender on fruit consumption shows that females are very slightly better in fruit consumption ( mean $=2.063$, SD $=0.945$ ) than males (mean $=2.043, \mathrm{SD}=0.952)$. This difference was insignificant $(p>0.05)$. The value of $\operatorname{eta}^{2}(.000)$ further shows the negligible contribution of gender in explaining fruit consumption. Hence, gender is irrelevant in fruit consumption. The analysis of the influence of marital status on fruit consumption shows that married respondents exhibit greater fruit consumption (mean $=2.11, \mathrm{SD}=0.910$ ) when compared with the single (mean $=1.95, \mathrm{SD}=0.931)$, the divorced $($ mean $=1.75$, $\mathrm{SD}=0.979$ ) and the widowed (mean=1.85, $\mathrm{SD}=1.06$ ). This difference was insignificant $(p>0.05)$. In similarity to gender, marital status has no main effect on fruit consumption, but descriptive statistics shows that married respondents exhibit greater fruit consumption. This is probably because married people are more predisposed to living more 'homely' lifestyles. $\mathrm{Eta}^{2}$ is 0.10 , implying that just about $1 \%$ of the variation in fruit consumption is accounted by marital status. The summary of results obtained in the analysis of the influence of gender and marital status on fruit consumption is presented in Table 1.

Table 1: Bivariate relationship between fruit consumption, gender and marital status

\begin{tabular}{|c|c|c|c|c|c|c|c|c|c|c|}
\hline & \multicolumn{2}{|c|}{$\begin{array}{l}\text { Levene's test for } \\
\text { homogeneity of variances }\end{array}$} & \multicolumn{2}{|c|}{ ANOVA } & \multicolumn{2}{|c|}{$\begin{array}{l}t \text { test for equality of } \\
\text { means }\end{array}$} & \multicolumn{2}{|c|}{$\begin{array}{l}\text { Robust test for } \\
\text { equality of means } \\
\text { (Brown-Forsythe's } \\
\text { test) }\end{array}$} & \multirow[t]{2}{*}{ Eta } & \multirow[t]{2}{*}{$\mathrm{Eta}^{2}$} \\
\hline & $\begin{array}{l}\text { Levene's } \\
\text { statistic }\end{array}$ & Sig. & $\mathrm{F}$ & Sig. & $\mathrm{T}$ & Sig. & statistic & Sig. & & \\
\hline Gender & .206 & .650 & - & - & .064 & .801 & .064 & .801 & .011 & .000 \\
\hline $\begin{array}{l}\text { Marital } \\
\text { Status }\end{array}$ & .501 & .682 & 1.865 & .134 & - & - & 1.724 & .181 & .100 & 0.10 \\
\hline
\end{tabular}

Dependent variable: Fruit consumption 
The analysis of relations between fruit consumption and fruity response efficacy yielded a Pearson's $r$ of $0.211, R^{2}$ of 0.044 and a standardized $\beta$ of 0.217 $(p<0.05)$. A similar assessment between fruit consumption and age yielded a Pearson's $r$ of 0.108 $(p>0.05), R^{2}$ of 0.014 and a standardized $\beta$ of 0.119 $(p<0.05)$. Further, relations between fruit consumption and education is depicted by a Pearson's $r$ of $0.105(p>0.05)$ and a standardized $\beta$ of $0.095(p<0.05)$. In addition, relations between fruit consumption and financial standing is depicted by a Pearson's $r$ of $0.063(p>0.05)$ and a standardized $\beta$ of 0.061 ( $p>0.05)$. These results show that fruity response efficacy is the best predictor of fruit consumption, followed age. Education and financial standing are no predictors of fruit consumption, as they demonstrated insignificant relationship with fruit consumption. These findings are quite complicatedintuitively, fruity response efficacy was best in predicting fruit consumption. Age, which predisposes increasing sense of responsibility, is a fair predictor of fruit consumption. Counter-intuitively, education, which usually improves life chances and financial capability, which presumably increases access to fruits, are no predictors of fruit consumption. Nevertheless, this counter-intuitiveness can be considered interesting as it imply that individuals' general education background and financial conditions are not necessarily barriers to fruit consumption in this target population. This claim is substantiated by the fact that different fruits are usually in season throughout they year. When they are, they are usually cheap and very much available. The summary of results obtained in the analysis of the influence of fruity response efficacy, age, education and financial standing on fruit consumption is presented in Table 2.

Table 2: Bivariate relationship between fruit consumption, fruity response efficacy, age, education and financial standing.

\begin{tabular}{|l|l|l|l|l|l|l|}
\hline & Pearson's $r$ & $p$ value & $\mathrm{R}^{2}$ & $p$ value & $\mathrm{B}$ & $p$ value \\
\hline $\begin{array}{l}\text { Fruity } \\
\text { Response } \\
\text { efficacy }\end{array}$ & .211 & .000 & .044 & .000 & .217 & .000 \\
\hline Age & .108 & .010 & .014 & .009 & .119 & .009 \\
\hline Education & .105 & .012 & - & - & .095 & .037 \\
\hline $\begin{array}{l}\text { Financial } \\
\text { Standing }\end{array}$ & .063 & .088 & - & - & .061 & .179 \\
\hline
\end{tabular}

Dependent variable: Fruit consumption

\section{CONCLUSION}

Individuals' perception of the role of fruit consumption in health optimization is singularly most important determinant of fruit consumption in this study. Being older and married are fairly important. This point to the need improve the level of awareness with regard to the worth of fruit consumption in health optimization. Gender, education and financial standing are not important factors in fruit consumption.

\section{REFERENCES}

Beutel, A.M. and Marini, M.M. (1995). Gender and Values. American Sociological Review, 60:436-448

Bingham, C.M., Jallinoja, P., Lahti-Koski, M., Absetz, P., Paturi, M., Pihlajamaki, H., Sahi, T., Uutela, A. (2010). Quality of diet and food choices of Finnish young men: a socio-demographic and health behaviour approach. Public Health Nutrition, 13(6A):980-6.

Boutayeb, A. and Boutayeb, S. (2005). The burden of non communicable diseases in developing countries. International Journal for Equity in Health, 4:2.

Daar, A.S., Singer, P.A., Persad, D.L., Pramming, S.K., Matthews, D.R., Beaglehole, R., Bernstein, A., Borysiewicz, L.K., Colagiuri, S., Ganguly, N., Glass, R.I., Finegood, D.T., Koplan, J., Nabel, E.G., Sarna, G., Sarrafzadegan, N., Smith, R., Yach, D. \& Bell, J. (2007). Grand challenges in chronic noncommunicable diseases. Nature, 450: 494-496.

Demark-Wahnefried, W., Morey, M.C., Sloane, R., Snyder, D.C., Cohen, H.J. (2009). Promoting healthy lifestyles in older cancer survivors to improve health and preserve function. Journal of American Geriatrics Society, 57 Suppl 2:S262-4.

French, S.A. and Stables, G. (2003). Environmental interventions to promote vegetable and fruit 
consumption among youth in school settings. Preventive Medicine, 37(6) 593-610.

Frongillo, E.A., Isaacman, T.D., Horan, C.M., Wethington, E., Pillemer, K. (2010). Adequacy of and satisfaction with delivery and use of home-delivered meals. Journal of Nutrition for the Elderly, 29(2):211-26.

Gandini, S., Merzenich, H., Robertson, C. and Boyle, P. (2000). Meta-analysis of studies on breast cancer risk and diet: the role of fruit and vegetable consumption and the intake of associated micronutrients. European Journal of Cancer, 36(5) 636-646.

Hall, J.N., Moore, S., Harper, S.B. and Lynch, J.W. (2009). Global Variability in Fruit and Vegetable Consumption. American Journal of Preventive Medicine, 36(5) 402409.

Hoppu, U., Lehtisalo, J., Tapanainen, H., Pietinen, P. (2010). Dietary habits and nutrient intake of Finnish adolescents. Public Health Nutrition, 13(6A):965-72.

Horwath, C.C., Nigg, C.R., Motl, R.W., Wong, K.T., Dishman, R.K. (2010). Investigating fruit and vegetable consumption using the transtheoretical model. American Jornal of Health Promotion, 24(5):324-33

Kimani-Murage, E.W., Kahn, K., Pettifor, J.M., Tollman, S.M., Dunger, D.B., Gomez-Olive, X.F., Norris, Ula S.A., (2010). The prevalence of stunting, overweight and obesity, and metabolic disease risk in rural South African children. BMC Public Health, 25,10,158.

Kremers, S.P.J., Brug, J., Vries, H.D. and Engels, C.M.E. (2003). Parenting style and adolescent fruit consumption. Appetite, 41(1) 43-50.

Moreno, L.A., Rodriguez, G., Fleta, J., Bueno-Lozano, M., Lazaro, A., Bueno, G. (2010). Trends of dietary habits in adolescents. Critical Review in Food Science and Nutrition, 50(2):106-12.

Oladapo, O.O., Salako, L., Sodiq, O., Shoyinka, K., Adedapo, K., Falase, A.O. (2010). A prevalence of cardiometabolic risk factors among a rural Yoruba south-western Nigerian population: a population-based survey. Cardiovascular Journal of Africa, 21(1), 26-31.

Pearson, T.A. (1996). Cardiovascular disease in developing countries; Myths, realities and opportunities. Cardiovascular Drugs Therapy, 13, 95104.

Reynolds, K.D., Agnes W. Hinton, A.W., Shewchuk, R.M. and Hickey, C.A. (1999). Social Cognitive Model of
Fruit and Vegetable Consumption in Elementary School Children. Journal of Nutrition Education, 31(1) 23-30.

Robertson, A., Tirado, C., Lobstein, T., Jermini, M., Knai, C., Jensen, J. (2004). Food and health in Europe: a new basis for action. Copenhagen: WHO Regional Publications (European Series; No. 96)

Rogers RW. (1983). Cognitive and Physiological Processes in Fear Appeals and Attitude Change: A Revised Theory of Protection Motivation. In Cacioppo JT, Petty RE. (ed.) Social Psychophysiology: A source book. New York, Guilford Press.

Schneider, M., Norman, R., Steyn, N. and Bradshaw, D. (2007). South African Comparative Risk Assessment Collaborating Group Estimating the burden of disease attributable to low fruit and vegetable intake in South Africa in 2000. South African Medical Journal, 97(8 Pt 2):717-23

Story, M., Neumark-Sztainer, D., Resnick, M.D. and Blum, R.W. (1998). Psychosocial Factors and Health Behaviors Associated with Inadequate Fruit and Vegetable Intake among American-Indian and AlaskaNative Adolescents. Journal of Nutrition Education, 30(2) 100-106.

Stroebe, W. (2000). Social Psychology and Health. Buckingham, Open University Press.

Townsend, M.S., Kaiser, L.L., Murphy, S.P. and Bunch, S.J. (1998). Psychosocial Variables Related to Fruit and Vegetable Consumption in Food Stamp Recipients. Journal of the American Dietetic Association, 98(9), Supplement 1, Page A20.

Unachukwu, C.N., Agomuoh, D.I., and Alasia, D.D. (2008) Pattern of non-communicable diseases among medical admissions in Port Harcourt, Nigeria. Nigerian Journal of Clinical Practice, 11(1):14-7.

World Health Organization (2003). Diet, Nutrition and Prevention of Chronic Diseases. Report of a joint FAO/WHO Expert Consultation, Geneva (WHO Technical Report Series, No. 916).

Yeh, M., Obenchain, J. and Viladrich, A. (2010). Barriers and Facilitating Factors Affecting Fruit and Vegetable Consumption. Bioactive Foods in Promoting Health, 85-98. 